\title{
Acute $\gamma$-Secretase Inhibition of Nonhuman Primate CNS Shifts Amyloid Precursor Protein (APP) Metabolism from Amyloid- $\beta$ Production to Alternative APP Fragments without Amyloid- $\beta$ Rebound
}

\author{
Jacquelynn J. Cook, ${ }^{3 *}$ Kristin R. Wildsmith, ${ }^{1 *}$ David B. Gilberto, ${ }^{4}$ Marie A. Holahan, ${ }^{3}$ Gene G. Kinney, ${ }^{5}$ \\ Parker D. Mathers, ${ }^{4}$ Maria S. Michener, ${ }^{3}$ Eric A. Price, ${ }^{5}$ Mark S. Shearman, ${ }^{5}$ Adam J. Simon, ${ }^{5}$ Jennifer X. Wang, ${ }^{2}$ \\ Guoxin $\mathrm{Wu},{ }^{5}$ Kevin E. Yarasheski, ${ }^{2}$ and Randall J. Bateman ${ }^{1}$ \\ Departments of ${ }^{1}$ Neurology and ${ }^{2}$ Medicine, Washington University School of Medicine, St. Louis, Missouri 63110, and Departments of ${ }^{3}$ Imaging, \\ ${ }^{4}$ Laboratory Animal Resources, and ${ }^{5}$ Neuroscience, Merck Research Laboratories, West Point, Pennsylvania 19486
}

\begin{abstract}
The accumulation of amyloid $\beta(\mathrm{A} \beta)$ in Alzheimer's disease is caused by an imbalance of production and clearance, which leads to increased soluble $\mathrm{A} \beta$ species and extracellular plaque formation in the brain. Multiple $\mathrm{A} \beta$-lowering therapies are currently in development: an important goal is to characterize the molecular mechanisms of action and effects on physiological processing of $\mathrm{A} \beta$, as well as other amyloid precursor protein (APP) metabolites, in models which approximate human A $\beta$ physiology. To this end, we report the translation of the human in vivo stable-isotope-labeling kinetics (SILK) method to a rhesus monkey cisterna magna ported (CMP) nonhuman primate model, and use the model to test the mechanisms of action of a $\gamma$-secretase inhibitor (GSI). A major concern of inhibiting the enzymes which produce $\mathrm{A} \beta$ ( $\beta$ - and $\gamma$-secretase) is that precursors of $\mathrm{A} \beta$ may accumulate and cause a rapid increase in $\mathrm{A} \beta$ production when enzyme inhibition discontinues. In this study, the GSI MK-0752 was administered to conscious CMP rhesus monkeys in conjunction with in vivo stable-isotope-labeling, and dose-dependently reduced newly generated CNS A $\beta$. In contrast to systemic $\mathrm{A} \beta$ metabolism, CNS A $\beta$ production was not increased after the GSI was cleared. These results indicate that most of the CNS APP was metabolized to products other than $A \beta$, including $C$-terminal truncated forms of $A \beta: 1-14,1-15$ and 1-16; this demonstrates an alternative degradation pathway for CNS amyloid precursor protein during $\gamma$-secretase inhibition.
\end{abstract}

\section{Introduction}

The amyloid hypothesis proposes that the accumulation of amyloid- $\beta(\mathrm{A} \beta)$ in the brain leads to a cascade of events culminating in Alzheimer's disease (AD) (Hardy and Selkoe, 2002; Golde, 2005). A $\beta$ is generated by the sequential cleavage of amyloid precursor protein (APP) by $\beta$-secretase and $\gamma$-secretase (Blennow et al., 2006; Steiner et al., 2008; Wolfe,

\footnotetext{
Received March 17, 2010; accepted March 31, 2010.

We gratefully acknowledge support from a Merck collaborative research grant (K.R.W. and R.J.B.), National Institute on Aging Grant K23 AG030946 (R.J.B.), National Institute of Neurological Disorders and Stroke Grant R01-NS065667 (R.J.B.), National Institutes of Health (NIH)-supported Washington University Neuroscience Blueprint Interdisciplinary Center Core Grant (P30 NS057105) (R.J.B.), the Knight Initiative for Alzheimer's Research (R.J.B.), Alzheimer's Disease Research Grant A2008-345 (K.R.W. and R.J.B.), a program of the American Health Assistance Foundation, and the NIH-supported Washington University Biomedical Mass Spectrometry Research Facility (P30-RR000954) (K.E.Y.). We thank Mary Beth Young for PK analysis, Tim Harrison for $\gamma$-secretase medicinal chemistry, and Paul McCracken for the MRI. A special thanks to Dr. Larry Handt for clinical care of this colony of rhesus monkeys and to Merck Research Laboratories West Point veterinary associates for weekly port maintenance.

R.J.B. is a cofounder of C2N Diagnostics, which has licensed some of the technology described from Washington University. J.J.C., D.B.G., M.A.H., G.G.K., P.D.M., M.S.M., E.A.P., M.S.S., and A.J.S. are or were employees of Merck Research Laboratories, a sponsor of this study.

*J.J.C. and K.R.W. contributed equally to this publication.

Correspondence should be addressed to Randall J. Bateman, Department of Neurology, Washington University School of Medicine, 660 S. Euclid Avenue, Box 8111, St. Louis M0 63110. E-mail: batemanr@wustl.edu.

DOI:10.1523/JNEUROSCI.1381-10.2010

Copyright $\odot 2010$ the authors $\quad 0270-6474 / 10 / 306743-08 \$ 15.00 / 0$
}

2008b). $A \beta$ accumulation in the form of insoluble plaques and soluble monomers and oligomers develops due to an imbalance in the production and clearance of these $\mathrm{A} \beta$ forms in the CNS.

Because $\mathrm{A} \beta$ is a major therapeutic target, multiple $\mathrm{A} \beta$-lowering strategies are under development, such as increasing clearance (including $\mathrm{A} \beta$ immunization approaches) or decreasing production by inhibition of $\beta$-secretase or $\gamma$-secretase (Hock et al., 2003; Lemere et al., 2004; Vassar, 2004; Wolfe, 2008a; Tomita, 2009). $\gamma$-Secretase is a complex of integral membrane proteins that are present in most cells, but may have different functions depending on cell type (Steiner et al., 2008). $\gamma$-Secretase inhibitors (GSIs) target the $\gamma$-secretase complex to inhibit the production of $\mathrm{A} \beta$ from the $\beta$-Cterminal fragment of APP. However, GSIs also inhibit notch processing, thereby interfering with the critical role of notch in signaling cell differentiation in the immune system and gastrointestinal tract (Maillard et al., 2003; Stanger et al., 2005). Chronic inhibition with a GSI leads to mechanism-based toxic side-effects (Searfoss et al., 2003; Wong et al., 2004), which may be avoided by using partial or intermittent $\gamma$-secretase inhibition. However, there is a concern that when $\gamma$-secretase inhibition is partial or intermittent, accumulated APP products, including the $\beta$-C-terminal fragment, will result in $\mathrm{A} \beta$ overshoot or rebound. 
After GSI treatment, a rebound in levels of $\mathrm{A} \beta$ above placebo is consistently observed in plasma of humans and animal models (Lanz et al., 2004, 2006; Michener et al., 2006; Rosen et al., 2006; Siemers et al., 2006). In addition, an early elevation in plasma $\mathrm{A} \beta 40$ has also been observed in rhesus monkeys at GSI doses that do not reduce plasma A $\beta 40$ (Michener et al., 2006). Although an overshoot was reported in the CNS of a rat model (Burton et al., 2008), it has not been observed in the CNS of human volunteers (Rosen et al., 2006) or other animal models (Lanz et al., 2004). The contrasting results observed in plasma versus the CNS highlight the separation of the periphery from the CNS and indicate potentially different molecular mechanisms of $A \beta$ production and APP processing. As increased concentrations of $A \beta$ in the CNS are expected to be harmful, it is important to demonstrate that candidate compounds are truly targeting $\mathrm{A} \beta$ generation in the CNS. Clarification of the specific effect on the processing of APP metabolites is also important for the selection of optimal compounds for development. As few treatments or conditional experiments can be evaluated in humans, we translated a recently described stable-isotope-labeling kinetic (SILK) method (Bateman et al., 2006) to a nonhuman primate model for testing of therapeutics and molecular mechanisms. By administering stable-isotopes in conjunction with a GSI, the effect of inhibition on $A \beta$ production was measured by liquid chromatography tandem mass spectrometry (LC-MS/MS). Similar to results seen in humans (Bateman et al., 2009), there was a dose-related decrease in $\mathrm{A} \beta$ production in response to $\gamma$-secretase inhibition without an overshoot of either newly generated or total levels of $\mathrm{A} \beta$.

\section{Materials and Methods}

Cisterna magna ported rhesus monkey model. All procedures related to the use of animals in these studies were reviewed and approved by the Institutional Animal Care and Use Committee at Merck Research Laboratories at West Point, and conform with the Guide for the Care and Use of Laboratory Animals (Institute of Laboratory Animal Resources, National Research Council, 1996). The chronically implanted cisterna magna catheter and port system provides for noninvasive collection of uncontaminated CSF samples and the capability for repeat sampling. This chronic system allows for longitudinal studies and comparison to historical data within the same monkeys. A customized flexible silicone catheter (SoloCath) is freely suspended in the cisterna magna, anchored firmly on both sides of the atlanto-occipital membrane, and tunneled subcutaneously to the midscapular region where it is fed into a surgically implanted port body. CSF is accessed by aseptically inserting a needle through the skin and membrane covering the port into the reservoir of the port body (Gilberto et al., 2003); CSF flows through the cannulation system without the need for active withdrawal. These monkeys are also implanted with a standard catheter system in the jugular vein (titanium vascular access port by SoloPort) for chronic vascular access used for the ${ }^{13} \mathrm{C}_{6}$-leucine infusions.

${ }^{13} C_{6}$-Leucine infusion protocol. In preparation for each experiment, rhesus monkeys were restricted to a diet of vegetables and fruit for a $24 \mathrm{~h}$ period before the start of the ${ }^{13} \mathrm{C}_{6}$-leucine infusion; all food was removed $\sim 17 \mathrm{~h}$ before dosing. Vegetables and fruit were provided again after the $8 \mathrm{~h}$ sample collection (during the infusion) and the normal diet of monkey chow (includes protein) was given after the termination of the infusion $(+12 \mathrm{~h}$ in the final standard protocol). Conscious monkeys were transferred to the laboratory and placed in primate restraint chairs; a $22 \mathrm{~g}$ Huber needle (Instech) connected to a sterile adapter was inserted into the port body to prepare the cisterna magna catheter and port system for CSF sampling. A sterile stock solution of ${ }^{13} \mathrm{C}_{6}$-leucine (Cambridge Isotope Laboratories, CLM-2262) was made fresh daily for each study at 15 or $7.5 \mathrm{mg} / \mathrm{ml}$ in saline for the high $(8 \mathrm{mg} / \mathrm{kg}+8 \mathrm{mg} / \mathrm{kg} / \mathrm{h})$ and low $(4$ $\mathrm{mg} / \mathrm{kg}+4 \mathrm{mg} / \mathrm{kg} / \mathrm{h}$ ) leucine infusions, respectively. The ${ }^{13} \mathrm{C}_{6}$-leucine was infused in the chronic vascular access port at $\sim 0.5 \mathrm{ml} / \mathrm{min}$ or $\sim 0.1$ $\mathrm{ml} / \mathrm{min}$ for the bolus and 12 or $21 \mathrm{~h}$ infusions (exact rate was normalized for body weight). Baseline CSF and blood samples were collected $1 \mathrm{~h}$ before the start of the $10 \mathrm{~min}$ primed bolus injection. In the final, optimized $(12 \mathrm{~h}$ ) protocol, plasma and CSF samples were also collected following the initiation of the ${ }^{13} \mathrm{C}_{6}$-leucine infusion at $2 \mathrm{~h}$ (11:00 A.M.), $4 \mathrm{~h}$ (1:00 P.M.), 6 h (3:00 P.M.), 8 h (5:00 P.M.), 12 h (9:00 P.M., end of infusion), 15 h (12:00 A.M.), 18 h (3:00 A.M.), 21 h (6:00 A.M.), 24 h (9:00 A.M., day 2), 27 h (12:00 P.M.), 30 h (3:00 P.M.), 33 h (6:00 P.M.), 36 h (9:00 P.M., day 3 ) and 39 h (12:00 P.M.). CSF (1 ml) was collected per time point, and samples were separated into aliquots and transferred to various laboratories for blinded analyses.

$\gamma$-Secretase inhibitor study protocol. The Merck $\gamma$-secretase inhibitor, MK-0752, was previously characterized for in vivo pharmacokinetics and efficacy, and demonstrated decline of CSF A $\beta 40$ levels in healthy human volunteers (Rosen et al., 2006). MK-0752 is a moderately potent $\gamma$-secretase inhibitor, showing dose-dependent reduction of $A \beta 40$ with an $\mathrm{IC}_{50}$ of $5 \mathrm{~nm}$ in human SH-SY5Y cells. Dose-dependent reductions in plasma, brain and CSF A $\beta 40$ were observed in guinea-pigs following single oral doses of $10-30 \mathrm{mg} / \mathrm{kg}$ (brain $\mathrm{IC}_{50}=440 \mathrm{~nm}$ ). Concentration required for $50 \%$ reduction of brain $\mathrm{A} \beta 40$ was 318 and $154 \mathrm{~nm}$ in APPYAC and Tg2576 mice, respectively. For the purposes of the current study, 60 and $240 \mathrm{mg} / \mathrm{kg}$ dose of MK-0752 were selected to elicit intermediate and near complete CSF A $\beta$ reduction for evaluating the potential effects on $\mathrm{A} \beta$ production and clearance. A 3-way crossover randomized design with 2 week intervals between doses in cisterna magna ported (CMP) rhesus monkeys was used $(n=6$ male rhesus monkeys; $n=5$ at $6-9$ years and $n=1$ at 17 years at time of study; $7-9.5$ $\mathrm{kg}$ ). MK-0752 (60 or $240 \mathrm{mg} / \mathrm{kg}$ ) or vehicle (water) was administered orally to conscious, chaired rhesus monkeys $1 \mathrm{~h}$ before the initiation of the primed $12 \mathrm{~h}^{13} \mathrm{C}_{6}$-leucine constant infusion $(4 \mathrm{mg} / \mathrm{kg}+4 \mathrm{mg} / \mathrm{kg} / \mathrm{h}$ ). CSF and plasma samples were collected as described above for determination of MK-0752 concentrations, $\mathrm{A} \beta 40$ (ELISA), ${ }^{13} \mathrm{C}_{6}$-leucine labeling of $\mathrm{A} \beta$, and free ${ }^{13} \mathrm{C}_{6}$-leucine enrichment.

To fully characterize the rebound beyond baseline in plasma $\mathrm{A} \beta 40$, a follow-up study was conducted. Six rhesus monkeys ( $n=3$ /group) were treated orally with vehicle or $240 \mathrm{mg} / \mathrm{kg}$ MK-0752. CSF and plasma samples were collected as described for the optimized protocol with the addition of time points through $240 \mathrm{~h}$ postdose $(48,72,144,168,216$, $240 \mathrm{~h})$.

Amyloid $\beta$ ELISA. Solid black 96 well Nunc plates were coated with 3 $\mu \mathrm{g} / \mathrm{ml} \mathrm{N}$-terminal $\mathrm{A} \beta$ antibody $6 \mathrm{E} 10$ (Signet) in $\mathrm{pH} 9.4$ bicarbonate buffer overnight at $4^{\circ} \mathrm{C}$, washed with PBS with $0.1 \%$ Tween 20 , and blocked with 3\% BSA in PBS (BSA/PBS) for $3 \mathrm{~h}$. CSF samples for the A $\beta 1-40$ assay were diluted 1:8 in BSA/PBS; $50 \mu \mathrm{l}$ of samples and standards, starting at 4:00 P.M., were loaded onto the plate. CSF samples for A $\beta 1$-42 were diluted 1:4 in BSA/PBS and $100 \mu \mathrm{l}$ of samples and standards, starting at 2:00 P.M., were loaded onto the plate. Plasma samples were diluted 1:4 in BSA/PBS and $50 \mu \mathrm{l}$ of samples and standards, starting at 4:00 P.M., were loaded onto the plate. Fifty microliters of G2-10alkaline phosphatase (A $\beta 1-40)$ or $12 \mathrm{~F} 4$-alkaline phosphatase (A $\beta 1-42)$ diluted in BSA/PBS was added to the plate and incubated overnight at $4^{\circ} \mathrm{C}$. Plates were washed 3 times in PBS with $0.1 \%$ Tween 20 and $100 \mu \mathrm{l}$ of alkaline phosphatase substrate Tropix CDP-star (Applied Biosystems) was added for $30 \mathrm{~min}$. Luminescence was measured using a PerkinElmer Envision plate reader.

Amyloid $\beta$ immunoprecipitation. Antibody beads were prepared by covalently binding $4 \mathrm{G} 8$ antibody (GE Healthcare) (recognizes $\mathrm{A} \beta$ residues 18-22) or 6E10 antibody (Covance) (recognizes $\mathrm{A} \beta$ residues 1-17) to $\mathrm{CNBr}$ Sepharose beads (GE Healthcare) at a concentration of 10 $\mathrm{mg} / \mathrm{ml}$ antibody (according to the manufacturer's protocol). The antibody beads were stored at $4^{\circ} \mathrm{C}$ in a $50 \%$ slurry of PBS $0.02 \%$ azide.

4 G8 immunoprecipitation. CSF $(500 \mu \mathrm{l})$ was diluted 1:1 with PBS. Protease inhibitors (40 $\mu \mathrm{g} / \mathrm{ml}$ aprotinin and $20 \mu \mathrm{g} / \mathrm{ml}$ leupeptin) (Calbiochem), $30 \mu \mathrm{l}$ of antibody-bead slurry, and guanidine (final concentration of $0.5 \mathrm{M}$ ) in Tris-HCl buffer $\mathrm{pH} 8$ were added to the diluted CSF, and samples were rotated overnight at $4^{\circ} \mathrm{C}$. The beads were rinsed once with $0.5 \mathrm{~m}$ guanidine and twice with $25 \mathrm{~mm}$ ammonium bicarbonate, with centrifugation in between rinses. They were aspirated dry after the final rinse and $\mathrm{A} \beta$ was eluted from the antibody-bead complex using 50 $\mu l$ of neat formic acid. After centrifuging the beads again, the formic acid 
A

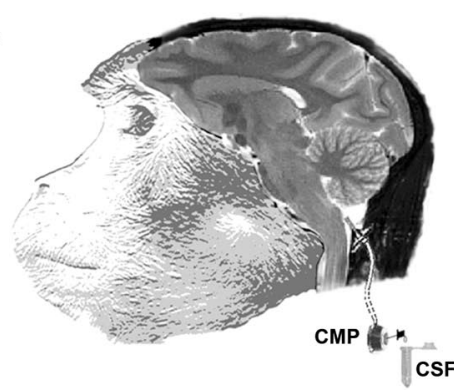

B

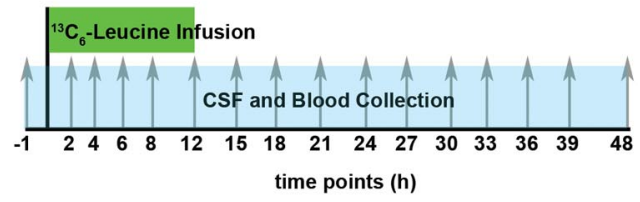

C

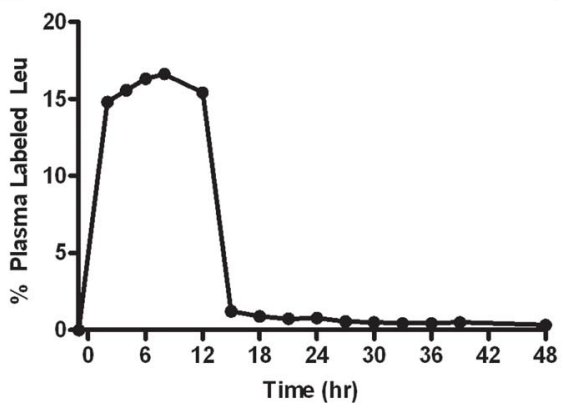

D

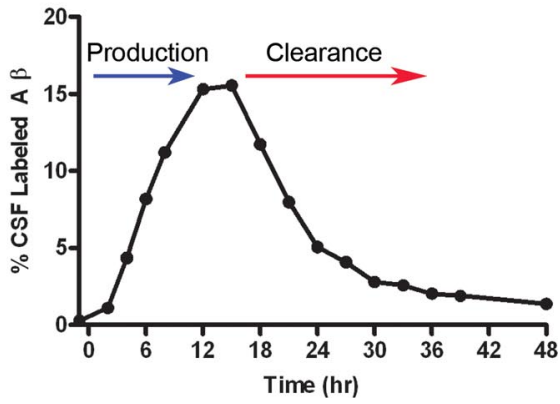

Figure 1. Illustration of A $\beta$ stable-isotope-labeling kinetics study in CMP rhesus monkeys. $A$, CSF is collected from the cisterna magna of the rhesus monkey. $B,{ }^{13} C_{6}$-leucine is infused from 0 to $12 \mathrm{~h}$, and $\mathrm{CSF}$ collected from -1 to $48 \mathrm{~h} . \boldsymbol{C}_{,}{ }^{13} \mathrm{C}_{6}$-leucine (Leu) is present in the plasma for the duration of infusion. $D$, The ${ }^{13} C_{6}$-leucine-labeled $A \beta$ in rhesus monkey $C N S$ increases during labeling (production phase) and decreases thereafter (clearance phase).

supernatant was transferred to a new tube and evaporated in a rotary evaporator at $37^{\circ} \mathrm{C}$ for $30 \mathrm{~min}$. The dried extract was reconstituted in 20 $\mu \mathrm{l}$ of 9:1 ammonium bicarbonate $(25 \mathrm{~mm})$ : acetonitrile. The extract was digested with $400 \mathrm{ng}$ of sequence grade trypsin (Promega) prepared in 25 $\mathrm{mm}$ ammonium bicarbonate and incubated at $37^{\circ} \mathrm{C}$ for $18 \mathrm{~h}$.

6 E10 immunoprecipitation. Protease inhibitors and guanidine were added to CSF $(900 \mu \mathrm{l})$ as described above. In addition, samples were spiked with $100 \mathrm{fmol}(10 \mathrm{fmol} / \mu \mathrm{l})$ of isotope-labeled $\mathrm{A} \beta$ peptide $\mathrm{A} \beta 1-15\left[\mathrm{Ala}\left(\mathrm{U}_{-}{ }^{13} \mathrm{C}_{3},{ }^{15} \mathrm{~N}\right), \operatorname{Arg}\left(\mathrm{U}_{-}{ }^{13} \mathrm{C}_{6}, \mathrm{U}_{-}{ }^{15} \mathrm{~N}_{4}\right)\right.$, Gly $\left.\left(\mathrm{U}_{-}{ }^{13} \mathrm{C}_{2},{ }^{15} \mathrm{~N}\right)\right]$ (prepared in HPLC grade water) (Anaspec) before addition of $30 \mu \mathrm{l}$ of $6 \mathrm{E} 10$ bead slurry, after which they were rotated overnight at $4^{\circ} \mathrm{C}$. The beads were rinsed as described above and peptides and proteins were eluted from the antibody-bead complex using $50 \mu \mathrm{l}$ of neat formic acid. After centrifugation, the formic acid supernatant was transferred to autosampler vials and evaporated in a rotary evaporator at $37^{\circ} \mathrm{C}$ for $30 \mathrm{~min}$. The dried extract was reconstituted in $20 \mu \mathrm{l}$ of $5 \%$ acetonitrile in $0.1 \%$ formic acid.

Liquid chromatography-mass spectrometry. A $\beta$ extracts were analyzed on a Thermo-Finnigan LTQ equipped with a New Objective nanoflow ESI source. Peptides were separated by RP HPLC using an Eksigent 2D-LC nanoflow pump operating in 1D mode at a flow of $200 \mathrm{nl} / \mathrm{min}$. Five microliters of extract was injected onto a New Objective picofrit column packed to $10 \mathrm{~cm}$ with $5 \mu \mathrm{m}$ Magic C18aq packing material (Michrom). Mobile phase A consisted of $0.1 \%$ formic acid in water, and mobile phase B consisted of $0.1 \%$ formic acid in acetonitrile. The doubly charged species of $A \beta$ 17-28 were separated as previously described (Bateman et al., 2007b). The quadruply charged species of A $\beta 1-14,1-15$, 1-16, and 1-17 were separated by applying a linear gradient from 2 to $18 \%$ B over $30 \mathrm{~min}$, followed by a rise to $90 \%$ B over $5 \mathrm{~min}$, and returned to $2 \%$ B by 40 min.

Calculation of labeled protein ratio and quantitation of $A \beta 1-14,1-15$, $1-16$, and 1-17. Percentage of labeled $\mathrm{A} \beta$ was calculated as the ratio of all $b$ - and $y$-tandem MS ion intensities from ${ }^{13} \mathrm{C}_{6}-\mathrm{A} \beta$ 17-28 $(\mathrm{m} / \mathrm{z} 666.5)$ divided by all $b$ - and $y$-tandem MS ion intensities from A $\beta 17-28(\mathrm{~m} / z$ 663.5 ) as previously described (Bateman et al., 2007b). The peak areas for $\mathrm{A} \beta 1-14,1-15,1-16$, and 1-17 (MS ${ }^{2}$ total ion currents) were calculated and normalized to the $\mathrm{A} \beta 1-15$ isotope-labeled standard using Xcalibur's quantitation software. Results were exported to MS Excel. All statistical calculations were performed with GraphPad 5.0. The coefficient of variation for quantitation was $\leq 3.8 \%$ for triplicate injections of the same sample.

Gas chromatography-mass spectrometry and calculation of ${ }^{13} C_{6}$-leucine enrichment. Plasma and $\mathrm{CSF}^{13} \mathrm{C}_{6}$-leucine enrichment was quantified using capillary gas chromatography mass spectrometry (GC-MS; Agilent $6890 \mathrm{~N}$ gas chromatograph and Agilent 5973N mass selective detector). Leucine was converted to the heptafluorobutyric propyl ester derivative; ${ }^{13} \mathrm{C}_{6}$-leucine $(\mathrm{m} / \mathrm{z} 349$ and 355$)$ enrichment was quantified using GC-MS in negative chemical ionization mode (Yarasheski et al., 1992; Bateman et al., 2007b). ${ }^{13} \mathrm{C}_{6}$-Leucine enrichment was calculated as the tracer:tracee ratio (Wolfe et al., 2005). The GC-MS instrument response was calibrated using gravimetric standards of known isotope enrichment.

Calculations of fractional synthesis rate, fractional clearance rate, and newly generated $A \beta$. The fractional synthesis rate (FSR) and fractional clearance rate (FCR) were calculated in the traditional manner (Wolfe et al., 2005). FSR equals the slope of the labeled $\mathrm{A} \beta$ (hours 2-8) divided by plasma ${ }^{13} \mathrm{C}_{6}$-leucine enrichment (precursor pool for $\mathrm{A} \beta$ synthesis) during leucine infusion (hours $2-8$ ). FCR equals the slope of the natural logarithm of labeled $A \beta$ during the clearance phase (hours 18-33). Newly generated $\mathrm{A} \beta$ was calculated as previously described as the product of the percentage of labeled A $\beta$ (LC-MS results) and the total $\mathrm{A} \beta$ concentration (ELISA results) (Bateman et al., 2009). All statistical calculations were performed with GraphPad 5.0.

\section{Results}

\section{Translation of human CNS-SILK method for use in rhesus monkeys}

We adapted the human in vivo SILK method for use with CMP rhesus monkeys. A summary of the protocol is shown in Figure 1. ${ }^{13} \mathrm{C}_{6}$-Leucine is intravenously administered to CMP rhesus monkeys for $12 \mathrm{~h}$; CSF is collected from the cisterna magna port during and after administration (Fig. 1 A, B). Labeled leucine enrichment in plasma and CSF is measured by GC-MS (Yarasheski et al., 1992) (Fig. 1C). The incorporation of the label into $A \beta$ is quantitated by immunoprecipitation paired with LC-MS (Bateman et al., 2006, 2007b) (Fig. $1 D$ ), and the results are used to calculate production and clearance rates.

To translate the in vivo method from humans to monkeys, and to achieve similar ${ }^{13} \mathrm{C}_{6}-\mathrm{A} \beta$ labeling, two ${ }^{13} \mathrm{C}_{6}$-leucine infusion protocols were evaluated. CMP rhesus monkeys were infused with ${ }^{13} \mathrm{C}_{6}$-leucine $(8 \mathrm{mg} / \mathrm{kg} / \mathrm{h})$ for either 21 or $12 \mathrm{~h}$, and CSF was collected approximately every $3 \mathrm{~h}$ for up to $48 \mathrm{~h}$ (Fig. 2). The administration of $8 \mathrm{mg} / \mathrm{kg} / \mathrm{h}{ }^{13} \mathrm{C}_{6}$-leucine resulted in fourfold higher plasma ${ }^{13} \mathrm{C}_{6}$-leucine labeling than the ratios observed in humans (Bateman et al., 2006). Reduction of the infusion to 4 $\mathrm{mg} / \mathrm{kg} / \mathrm{h}{ }^{13} \mathrm{C}_{6}$-leucine for $12 \mathrm{~h}$ resulted in maximum plasma ${ }^{13} \mathrm{C}_{6}$-leucine labeling of $15 \%$, which is more similar to human studies, and thus was used for subsequent studies. The steadystate labeling of $\mathrm{A} \beta$ exceeded the theoretical maximum when CSF ${ }^{13} \mathrm{C}_{6}$-leucine levels were used as the precursor pool (Fig. $2 \mathrm{~A}, 21 \mathrm{~h}$ infusion). In contrast, the steady-state labeling of $A \beta$ approached and did not exceed the maximum when using plasma ${ }^{13} \mathrm{C}_{6}$ leucine levels (Fig. 2 B, $21 \mathrm{~h}$ infusion). For this reason, subsequent studies used plasma ${ }^{13} \mathrm{C}_{6}$-leucine levels for labeled $\mathrm{A} \beta$ normaliza- 
tion. By reducing the ${ }^{13} \mathrm{C}_{6}$-leucine infusion from 21 to $12 \mathrm{~h}$, more sample time points could be added to the $\mathrm{A} \beta$ clearance phase which enabled more accurate clearance rate calculations.

Intrasubject and intersubject variability for measurements of $\mathrm{A} \beta$ metabolism were analyzed and compared with steadystate levels as measured by ELISA. The same three animals were evaluated in two separate studies, and calculated FCRs were correlated between studies $(r=$ 0.9969; supplemental Fig. $1 A$, available at www.jneurosci.org as supplemental material). Different individual monkeys ( $n=$ 3) also showed similar FCRs with SEM between 0.3 and $0.5 \% / \mathrm{h}$ demonstrating some biological variability between monkeys (supplemental Fig. $1 B$, available at www.jneurosci.org as supplemental material). FSR and FCR results were compared with levels of $A \beta$. There was a positive correlation between FSR and FCR values and levels of $\mathrm{A} \beta(n=9$, FSR vs $\mathrm{A} \beta$ 40 Pearson $r=0.76, p=0.016$; FSR vs A $\beta 42$ Pearson $r=0.77, p=0.015$; FCR vs A $\beta 40$ Pearson $r=0.41, p=0.27$; FCR vs A $\beta 42$ Pearson $r=0.79, p=0.03$ ).

The $12 \mathrm{~h}$ optimized ${ }^{13} \mathrm{C}_{6}$-leucine (4 $\mathrm{mg} / \mathrm{kg} / \mathrm{h}$ ) infusion ( $n=12$ monkeys) demonstrated low intersubject variability for $\mathrm{A} \beta$ labeling kinetics at each time point sampled over $39 \mathrm{~h}$ (average SEM $=0.02$, $n=12$ ) (Fig. $3 A$ ). There were no significant differences observed between genders or across ages of the animals included in this study. The mean FSR (h 2-8) was $10.7 \pm 0.6 \% / \mathrm{h}(\mathrm{SEM})$ and the mean FCR (h $18-33$ ) was $9.9 \pm 0.5 \% /$ h (Fig. $3 B$ ); these values were not significantly different $(p=0.25)$.

\section{CNS-penetrant $\gamma$-secretase inhibitor decreases the generation} of newly produced $A \boldsymbol{\beta}$ in the brain of rhesus monkeys

In a three-way crossover study, healthy male CMP rhesus monkeys $(n=6)$ were treated with single oral administration of two doses of the CNS-penetrant GSI, MK-0752, and vehicle to evaluate effects on $\mathrm{A} \beta$ metabolism. MK-0752 concentrations were quantified in plasma (Fig. 4A) and CSF (Fig. 5A), showing peak concentration at $2 \mathrm{~h}$ with both doses. The majority of the drug was cleared from plasma and CSF by $36 \mathrm{~h}$. Effects of this GSI on $\mathrm{A} \beta$ concentrations in the plasma and CSF were quantified using ELISA and demonstrate a dose-related reduction of $\mathrm{A} \beta$ levels in plasma $(\mathrm{A} \beta 40)(p=0.0012)$ and $\mathrm{CSF}(\mathrm{A} \beta 40$ and $\mathrm{A} \beta 42)(p<$ 0.001 ) as determined by a repeated-measures ANOVA (Figs. $4 B$, $5 B, C)$. Plasma $A \beta$ levels rebounded above baseline after GSI inhibition $(60 \mathrm{mg} / \mathrm{kg})(p<0.001$ paired $t$ test vehicle vs $60 \mathrm{mg} / \mathrm{kg}$ h 33-48) (Fig. 4B); in contrast, CSF A $\beta$ levels did not overshoot baseline levels (Figs. $5 B, C$ ). In an extended study designed to evaluate the rebound response of the higher dose of $240 \mathrm{mg} / \mathrm{kg}$, an overshoot above baseline was observed in plasma $48 \mathrm{~h}$ after treatment $(p<0.001$ unpaired $t$ test vehicle vs $240 \mathrm{mg} / \mathrm{kg} \mathrm{h}$ 48-240) (Fig. 4D).

The GSI dose-dependently reduced newly synthesized CNS $\mathrm{A} \beta$ over $48 \mathrm{~h}$, without any evidence of a rebound or overshoot of bars represent SEM.

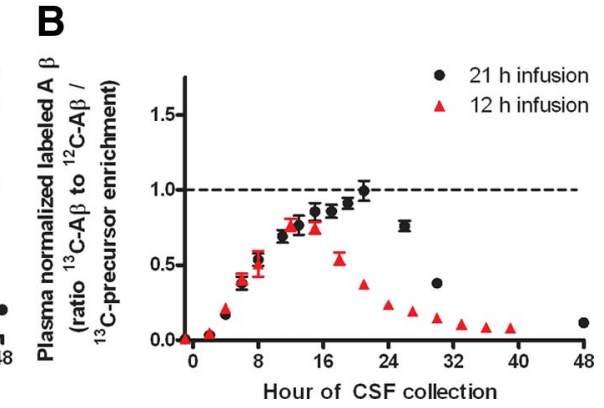

Figure 2. The duration of ${ }^{13} \mathrm{C}_{6}$-labeling does not affect $\mathrm{A} \beta$ production estimates, and plasma better reflects the ${ }^{13} \mathrm{C}_{6}$-leucine (bock, solid circle) or $12 \mathrm{~h}$ (red, solid triangle). The ratio of ${ }^{13} \mathrm{C}-\mathrm{A} \beta$ to ${ }^{12} \mathrm{C}-\mathrm{A} \beta$ from CSF was measured by LC-MS, and normalized

Figure 3. Rhesus monkey CNS A $\beta$ metabolism is similar to results observed in humans (Bateman et al., 2006). $\boldsymbol{A}$, Optimized

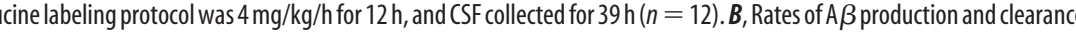
a rates were found to be consistent across $n=12$ rhesus monkeys. There was no significant difference between the means (t) Error bars indicate SEM.

newly generated CNS A $\beta$ (Fig. $6 A$ ). Similar results were observed in an extended study $(240 \mathrm{~h})$ with the $240 \mathrm{mg} / \mathrm{kg}$ GSI treatment (Fig. $6 B$ ) (unpaired $t$ test, $p=0.0009$ ). Area under the curve (AUC) analysis for newly generated $A \beta$ indicated a significant difference between the means of the vehicle and GSI treatment groups (ANOVA, $p<0.0001$ ). The mean AUC not only reflected a dose-dependent decrease during the ${ }^{13} \mathrm{C}_{6}$-leucine infusion $(0-12 \mathrm{~h})$ (Fig. 6C), but also during the entire study $(0-48 \mathrm{~h})$ (Fig. $6 D)$ (Tukey post hoc analysis, $p<0.001$ ). During the $48 \mathrm{~h}$ sampling period, the mean AUC of newly generated $\mathrm{A} \beta$ was reduced by $49 \%$ in the $60 \mathrm{mg} / \mathrm{kg}$ dose group and by $90 \%$ in the $240 \mathrm{mg} / \mathrm{kg}$ GSI dose group $(p<0.01)$ (Fig. 6D).

\section{CNS-penetrant $\gamma$-secretase inhibitor alters levels of noncanonical APP fragments}

To evaluate alternative pathways of APP degradation in the presence of $\gamma$-secretase inhibition, noncanonical forms of $\mathrm{A} \beta$ (e.g., $\mathrm{A} \beta$ not produced by $\beta$ - and $\gamma$-secretase cleavage) were measured in the CSF of rhesus monkeys ( $n=6,3$ /group) treated with a high dose of MK-0752 (240 mg/kg) versus vehicle. Four isoforms of $\mathrm{A} \beta$ ( $\mathrm{A} \beta$ 1-14, $\mathrm{A} \beta$ 1-15, $\mathrm{A} \beta$ 1-16, and $\mathrm{A} \beta$ 1-17) were quantified from the CSF using internal standard controls. In animals treated with the GSI, levels of $A \beta$ 1-14, $A \beta$ 1-15, and $A \beta$ 1-16 increased over vehicle levels, while levels of $\mathrm{A} \beta$ 1-17 decreased (unpaired $t$ test, $p<0.0001$, Fig. 7 ). The expected reductions in plasma $\mathrm{A} \beta 40$ and CSF $A \beta 40$ and $A \beta 42$ were demonstrated during the same time (Figs. $4 D, 5 E, F$ ), while plasma $\mathrm{A} \beta 40$ rebounded after $48 \mathrm{~h}$ (Fig. 4D). 
A
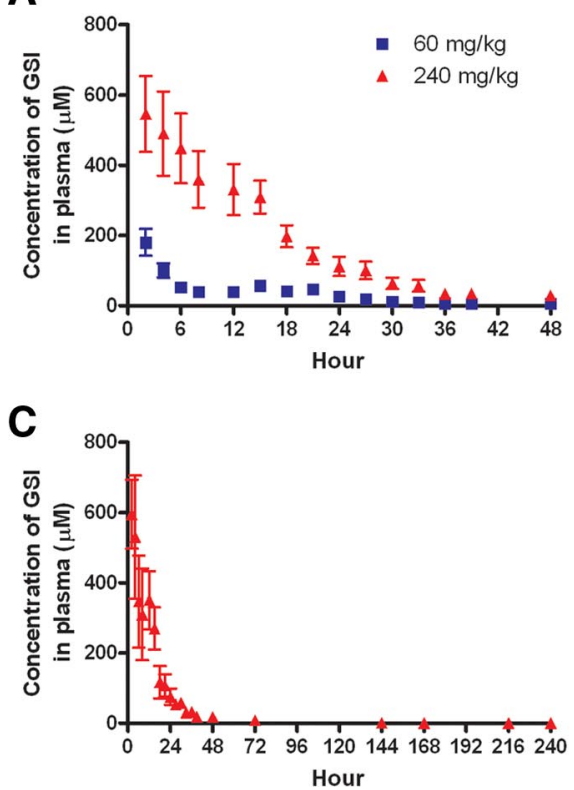

B
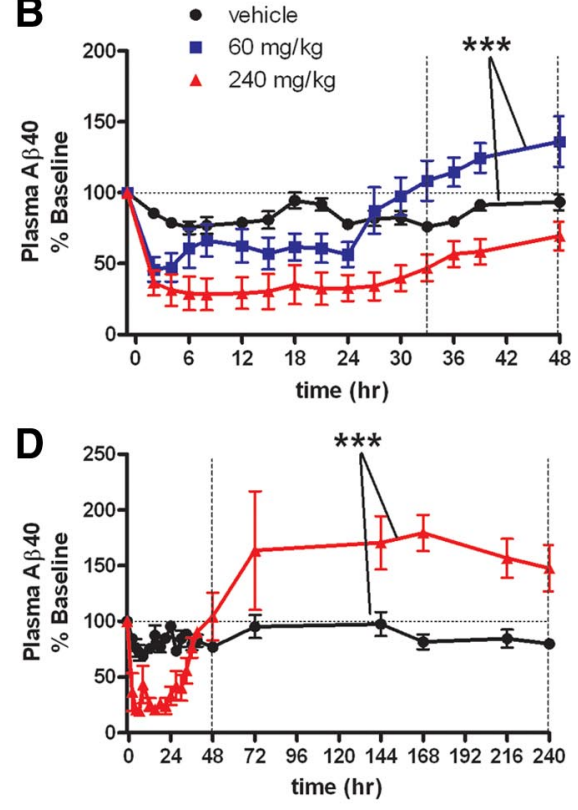

Figure 4. Plasma levels of $A \beta$ during and after $\gamma$-secretase inhibition indicate peripheral $A \beta$ rebound in rhesus monkeys treated with a CNS-penetrant GSI. $\boldsymbol{A}$, Concentration of GSI in rhesus monkey plasma after dosing with GSI. $\boldsymbol{B}, A \beta$ levels in rhesus monkeys $(n=6)$, measured by ELISA are shown normalized to baseline. A dose-response effect on $A \beta$ levels was observed with $60 \mathrm{mg} / \mathrm{kg}$ and $240 \mathrm{mg} / \mathrm{kg}$. Plasma $A \beta$ levels in the $60 \mathrm{mg} / \mathrm{kg}$ dose group recovered to baseline after $24 \mathrm{~h}$, and then increased above baseline. Means between vehicle and $60 \mathrm{mg} / \mathrm{kg}$ from hours $33-48$ are significantly different (paired $t$ test, $\left.{ }^{* * *} p<0.0001\right)$. C, D, In an extended study ( $n=6,3 /$ group), animals were treated with either vehicle or $240 \mathrm{mg} / \mathrm{kg} \mathrm{GSI}$. C, Concentration of GSI in rhesus monkey plasma after dosing with $240 \mathrm{mg} / \mathrm{kg}$ GSI. D, Plasma A $\beta$ levels overshoot baseline after $48 \mathrm{~h}$ in $240 \mathrm{mg} / \mathrm{kg}$ GSI-treated animals (unpaired $t$ test, ${ }^{* * *} p<0.0001, \mathrm{~h} 48-240$ ). (vehicle, black circle; $60 \mathrm{mg} / \mathrm{kg}$, blue square; $240 \mathrm{mg} / \mathrm{kg}$, red triangle). Error bars indicate SEM.

A
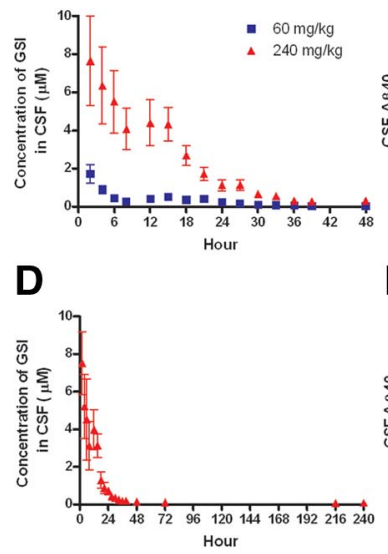

B

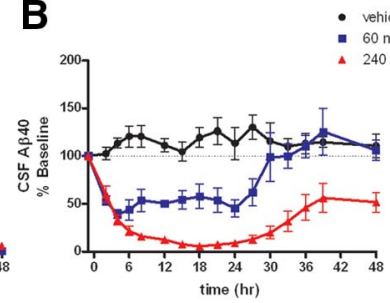

E

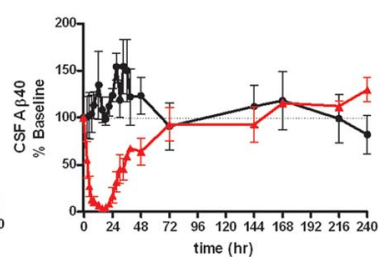

\section{C}

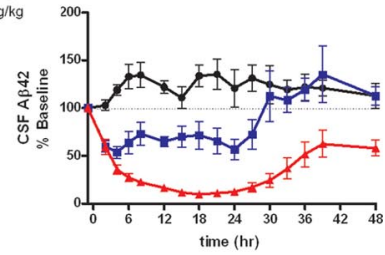

$F$

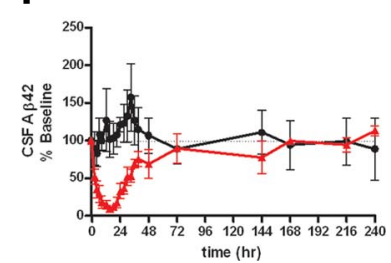

Figure 5. No evidence of central $A \beta$ rebound in rhesus monkeys treated with a CNS-penetrant GSI. $A$, Concentration of GSI in rhesus monkey CSF after dosing. $\boldsymbol{B}, \boldsymbol{C}, A \beta$ levels in rhesus monkeys $(n=6)$, measured by ELISA, were normalized to baseline. $A$ dose-response effect on $A \beta$ levels was observed with GSI treatment. A rebound effect was not observed in levels of CSF A $\beta 40(B)$ or $A \beta 42$ (C). After $48 \mathrm{~h}$, the $A \beta$ levels with $240 \mathrm{mg} / \mathrm{kg}$ treatment only recovered to $50 \%$ of baseline, while the $60 \mathrm{mg} / \mathrm{kg}$ treatment group reached baseline at $30 \mathrm{~h}$ without overshoot. $\boldsymbol{D}-\boldsymbol{F}$, In an extended study ( $n=6,3 /$ group) $\mathrm{A} \beta$ levels returned to baseline within $72 \mathrm{~h}$ of treatment ( $240 \mathrm{mg} / \mathrm{kg}$ ), without rebound. (vehicle, black circle; $60 \mathrm{mg} / \mathrm{kg}$, blue square; $240 \mathrm{mg} / \mathrm{kg}$, red triangle). Error bars indicate SEM.

\section{Discussion}

The results of this study demonstrate that $\mathrm{A} \beta$ metabolism in the rhesus monkey is similar to healthy humans (Bateman et al., 2006), which is expected because there are no significant amyloid plaques present in the rhesus monkey brain at this age (Struble et al., 1985). In conjunction with in vivo stable-isotope-labeling, new generation of CNS A $\beta$ was significantly reduced in response to $\gamma$-secretase inhibition. However, in contrast to the periphery, production of CNS $\mathrm{A} \beta$ did not rebound above baseline after cessation of inhibition. Defining the metabolic fate of APP in the CNS is critically important for the development of $\gamma$-secretase inhibitors to treat AD, as a substrate build-up of APP fragments could potentially lead to an overshoot in neurotoxic amyloid peptides. The lack of $\mathrm{A} \beta$ rebound in the CNS could be attributed to the shunting of APP (possibly $\beta$ C-terminal fragments, e.g., C99) to $\gamma$-secretase independent degradation. In support of this alternative, noncanonical processing, increased levels of APP fragments $A \beta 1-14,1-15$, and 1-16 were observed in CSF samples of animals treated with the GSI, while $\mathrm{A} \beta$ 1-17 was decreased. The CNS elimination of APP through nonamyloidogenic pathways strengthens the case for the use of $\gamma$-secretase as a therapeutic target for $\mathrm{AD}$ and may also be relevant for physiological processing of APP.

Many treatments have demonstrated efficacy in preclinical AD murine models; however, to date, none have been successful in clinical trials (Duff and Suleman, 2004). Failed translation from preclinical models to clinical studies may be a result of several reasons, including targeting of the wrong molecular mechanism of disease, failure to sufficiently modulate the target, or administration of the therapy too late in the course of the disease (Bateman and Klunk, 2008). For Alzheimer's disease, one limiting factor for translation from preclinical models to clinical trials is the lack of animal models that closely reflect human $\mathrm{A} \beta$ CNS physiology; such models would provide relevant information regarding the target, mechanism of action, and therapeutic effectiveness. Thus, there is a need to develop better models of therapeutic targets that would provide a bridge for the translation of $\mathrm{mu}$ rine models of amyloidosis to human trials in $\mathrm{AD}$.

The CMP rhesus monkey is a nonhuman primate model that enables repeat sampling of CSF (Gilberto et al., 2003; Nantermet et al., 2009; Sankaranarayanan et al., 2009). Pairing this model with in vivo SILK enables direct measurement of newly generated CNS proteins and peptides such as $\mathrm{A} \beta$. Results demonstrate that $\mathrm{A} \beta$ metabolism in the rhesus monkey is very similar to humans (Bateman et al., 2006), which indicate that the CMP rhesus monkey model can be used for preclinical drug discovery and development studies. Repeated measures (pre- and posttreatment) studies with a crossover design are especially powerful when coupled with the low intrasubject variability. 
This combination allows for the use of fewer monkeys to clearly answer research questions (Fig. 3; supplemental Fig. 1, available at www.jneurosci.org as supplemental material).

There are similarities and differences between the metabolism of $A \beta$ in rhesus monkeys and humans. As expected, the average FSR and FCR are balanced in both the rhesus monkey $(n=12)$ (Fig. $3 B)$ and human (Bateman et al., 2006). However, rhesus monkey CNS FSR and FCR are slightly faster than human CNS FSR and FCR $(\sim 10 \%$ per hour vs $\sim 8 \%$ per hour, respectively; Fig. 3B) (Bateman et al., 2006). Other than species differences, the observed disparity in $\mathrm{A} \beta$ metabolism may be due to CSF sampling location. Human CSF was sampled by lumbar intrathecal catheter, whereas monkey CSF was sampled at the cisterna magna at the base of the head (Fig. $1 A$ ). The more proximal sampling location could also explain the slightly shorter delay in ${ }^{13} \mathrm{C}_{6}$ incorporation observed in the monkeys versus that seen in humans ( $4 \mathrm{~h}$ vs $5 \mathrm{~h}$, respectively), which indicates that lumbar sampling only slightly delays the appearance of newly generated $\mathrm{A} \beta$. Prior human studies demonstrated individual changes in CSF A $\beta$ levels by $100-400 \%$ over several hours (Bateman et al., 2007a). In this study of nonhuman primate CSF, there were individual CSF A $\beta$ changes of $30-50 \%$. The group changes in $\mathrm{A} \beta$ levels were similar between human lumbar CSF samples and nonhuman primate CMP samples when averaged (25-50\% over a $24 \mathrm{~h}$ period). However, CMP monkey samples did not demonstrate a progressive rise in $\mathrm{A} \beta$ levels. Possible reasons for differences in the intrasubject CSF A $\beta$ variability and lack of CSF A $\beta$ rise include species differences, behavioral activity, site of sampling, frequency or amount of sampling, and sleep/wake cycle differences.

Findings in the nonhuman primate model also have implications for human studies. For example, in this study, we determined that plasma is more accurate than CSF for leucine precursor measurements of CNS A $\beta$ generation (Fig. 2). As the CSF normalized ratio exceeded the theoretical maximum of one, the CSF ${ }^{13} \mathrm{C}_{6}$-leucine is an underestimate of the precursor pool labeling. The labeled leucine precursor enrichment in monkey plasma is higher than CSF, similar to results observed in humans (Bateman et al., 2006). This suggests that plasma-labeled leucine measurements are more accurate for calculations of $\mathrm{A} \beta$ metabolism in human, as well as the nonhuman primate.
A

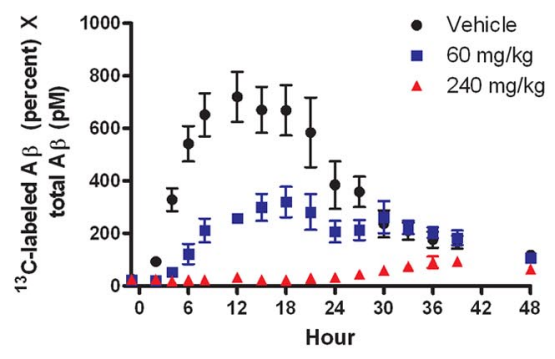

C

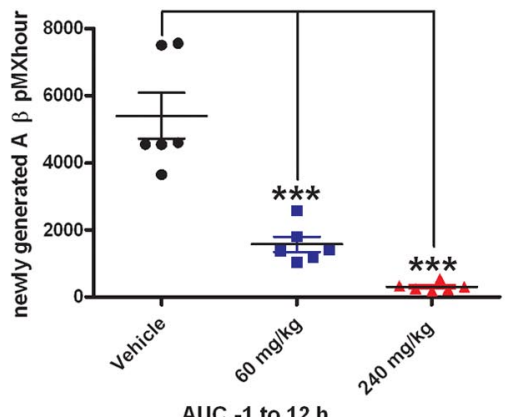

AUC -1 to $12 \mathrm{~h}$
B

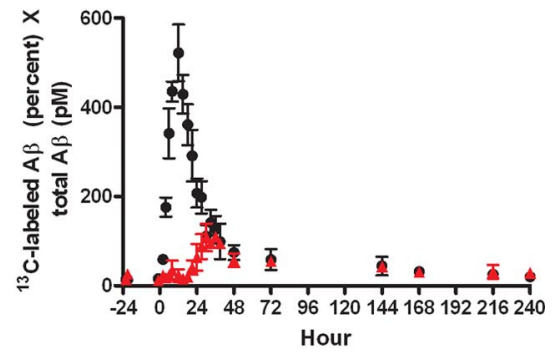

D

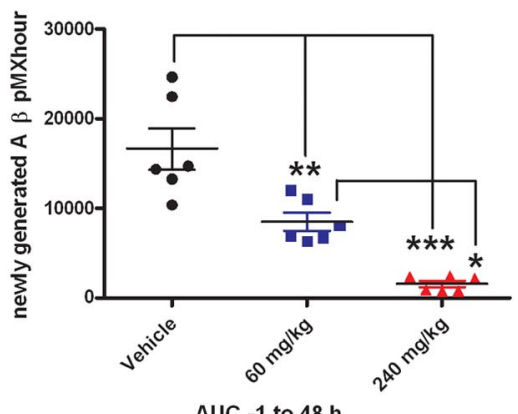

AUC -1 to $48 \mathrm{~h}$

Figure 6. Newly generated $A \beta$ was reduced in response to $G S I$ treatment in the $C N S$ of rhesus monkeys $(n=6) . A, C, D$, In a crossover study, male rhesus monkeys $(n=6)$ were infused with ${ }^{13} \mathrm{C}_{6}$-leucine $(4 \mathrm{mg} / \mathrm{kg} / \mathrm{h})$ for $12 \mathrm{~h}$, and treated with vehicle (black circle), $60 \mathrm{mg} / \mathrm{kg}$ GSI (blue square), or $240 \mathrm{mg} / \mathrm{kg} \mathrm{GSI}$ (red triangle). $\boldsymbol{B}$, In an extended study ( $n=6,3 / \mathrm{group}$ ), animals were treated with vehicle or $240 \mathrm{mg} / \mathrm{kg}$ GSI. $A, B$, Generation of new $A \beta$ was partially blocked with administration of $60 \mathrm{mg} / \mathrm{kg}$, and nearly completely blocked at the $240 \mathrm{mg} / \mathrm{kg}$ dose as indicated by the dose-dependent decrease in the amount of ${ }^{13} C_{6}$-leucine-labeled $A \beta$ (LC-MS). C, D, AUC analysis of newly generated $A \beta$ indicates that the means of newly synthesized $A \beta$ are significantly reduced by GSI treatment during the leucine infusion $(0-12 \mathrm{~h})(\boldsymbol{C})$ and levels do not recover within $48 \mathrm{~h}(\boldsymbol{D})$, as assessed by a repeated measures 1-way ANOVA $(p<0.0001)$ and post hoc analysis (Tukey) $\left({ }^{*} p=0.01\right.$ to $0.05 ;{ }^{* *} p=0.001$ to $\left.0.01 ;{ }^{* * *} p<0.001\right)$. Error bars indicate SEM.
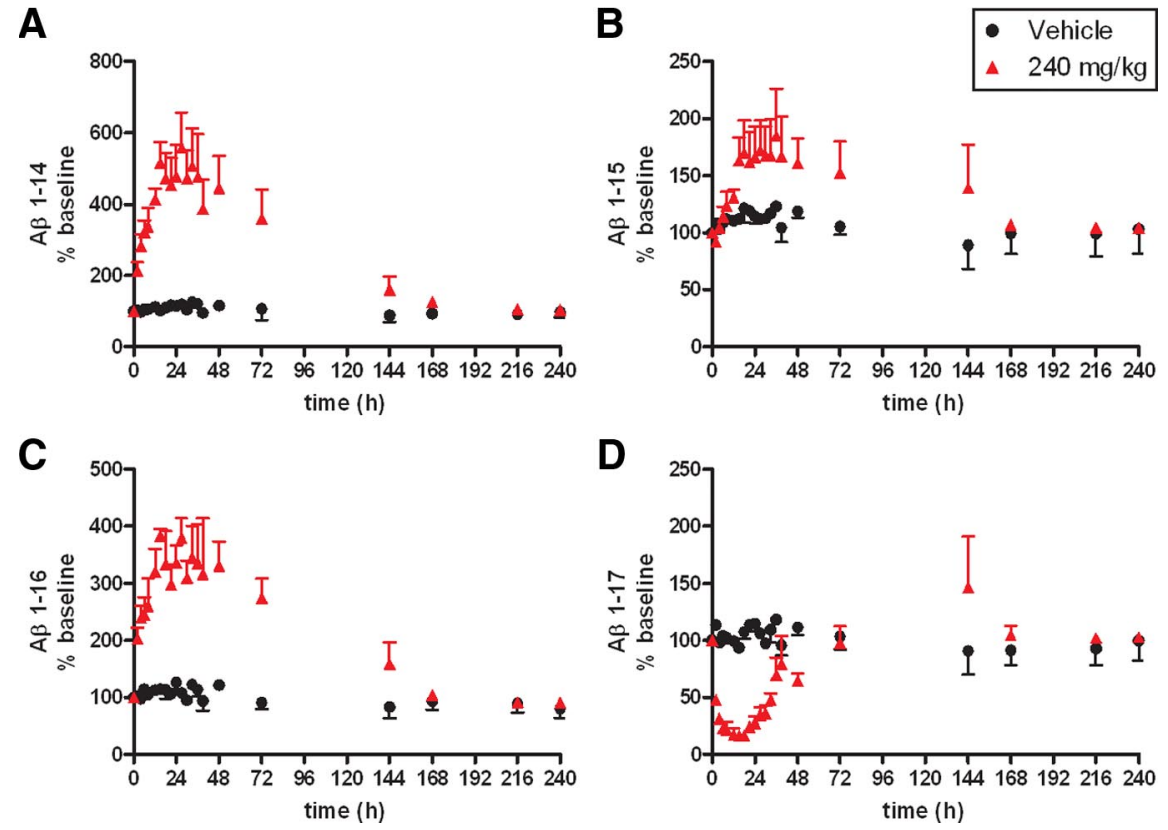

Figure 7. $\gamma$-Secretase inhibition modulates levels of $A \beta 1-14,1-15,1-16$, and 1-17. Rhesus monkeys ( $n=6, n=3$ /group) were treated with either vehicle (black, circle) or $240 \mathrm{mg} / \mathrm{kg} \mathrm{GSI}$ (red, triangle). An increase in levels of $A \beta$ 1-14 (A), A $\beta$ 1-15 (B), and $A \beta$ 1-16 (C) was observed in GSI versus vehicle-treated animals during $\gamma$-secretase inhibition. However, levels of $A \beta$ 1-17 (D) in treated animals were decreased versus vehicle. The means of the vehicle versus treated animals over $48 \mathrm{~h}$ were significantly different for $A \beta$ 1-14 (A), $A \beta$ 1-15 (B), $A \beta$ 1-16 (C), and $A \beta$ 1-17 (D) (unpaired $t$ test $p<0.0001$ ). 
The utility of this CMP rhesus monkey translational model was demonstrated by quantifying $A \beta$ metabolism before and after acute exposure to the GSI MK-0752. A prior human GSI SILK study indicates that a decrease in $\mathrm{A} \beta$ production can be measured to a sensitive degree (Bateman et al., 2009). In this nonhuman primate study, GSI efficacy (blocking $\mathrm{A} \beta$ production) and duration was higher compared with that observed in the human GSI study. Possible reasons for these observed differences include the GSI compound used, the dose of GSI administered, and, possibly, species differences. The extended effect may be due to the longer half-life of MK-0752 (10 h) in rhesus monkey versus LY450139 (2.5 h) in human (Siemers et al., 2005).

Consistent with previous observations (Lanz et al., 2004, 2006; Michener et al., 2006; Rosen et al., 2006; Siemers et al., 2006; Burton et al., 2008) plasma $A \beta$ levels did rebound after the GSI was cleared (Fig. 4). However, concentrations of $A \beta$ in the CSF did not overshoot baseline or placebo $A \beta$ levels (Fig. 5). Measurement of production rates directly confirms that this GSI reduced $\mathrm{A} \beta$ levels by decreasing the generation of new $\mathrm{A} \beta$ without a subsequent rebound (Fig. 6). These results suggest that the $\mathrm{A} \beta$ precursor is being degraded by another pathway during inhibition (Portelius et al., 2009). In vitro studies have suggested that in the presence of $\gamma$-secretase inhibition, $\beta$-secretase and $\alpha$-secretase generate $\mathrm{A} \beta 1-14,1-15$, and $1-16$, and that $\mathrm{A} \beta$ isoforms longer than 1-16 are reduced (Portelius et al., 2009). Our results support this hypothesis by demonstrating for the first time in a nonhuman primate model, the rise in $\mathrm{A} \beta 1-14,1-15$, and 1-16 with a concurrent decrease of $A \beta 1$ 1-17 (Fig. 7). Further, the time course of altered APP metabolites indicates that A $\beta$ 1-17 is possibly a cleavage product of $A \beta 1-40$ and $A \beta 1-42$, as all are decreased at similar times $(0-48 \mathrm{~h})$, while $\mathrm{A} \beta 1-14,1-15$, and 1-16 are increased during and after inhibition $(0-144 \mathrm{~h})$. Potential candidates known to cleave at the $\mathrm{A} \beta$ 1-17 site include endothelin converting enzyme, insulin-degrading enzyme, and matrix metalloproteinase-9 (Yan et al., 2006). These findings advance our understanding of the mechanisms of APP processing in the CNS, and provide novel information about the effects of GSI therapy on APP processing.

In conclusion, our study demonstrates that the effect of therapeutics developed to target $\mathrm{A} \beta$ production or clearance can be evaluated directly in a preclinical, nonhuman primate model. This will aid in the selection of clinical candidate compounds, and optimization of dose and timing of drug administration in a model which is similar to human $\mathrm{A} \beta$ physiology. In addition, molecular mechanisms of CNS protein processing can be explored by using therapeutics, which modulate key CNS enzymes with physiologically relevant models. These methods and findings hold promise to improve the likelihood of successful clinical trials for the treatment of Alzheimer's disease and other CNS disorders.

\section{References}

Bateman RJ, Klunk WE (2008) Measuring target effect of proposed diseasemodifying therapies in Alzheimer's disease. Neurotherapeutics 5:381-390.

Bateman RJ, Munsell LY, Morris JC, Swarm R, Yarasheski KE, Holtzman DM (2006) Human amyloid-beta synthesis and clearance rates as measured in cerebrospinal fluid in vivo. Nat Med 12:856-861.

Bateman RJ, Wen G, Morris JC, Holtzman DM (2007a) Fluctuations of CSF amyloid-beta levels: implications for a diagnostic and therapeutic biomarker. Neurology 68:666-669.

Bateman RJ, Munsell LY, Chen X, Holtzman DM, Yarasheski KE (2007b) Stable isotope labeling tandem mass spectrometry (SILT) to quantify protein production and clearance rates. J Am Soc Mass Spectrom 18:997-1006.
Bateman RJ, Siemers ER, Mawuenyega KG, Wen G, Browning KR, Sigurdson WC, Yarasheski KE, Friedrich SW, Demattos RB, May PC, Paul SM, Holtzman DM (2009) A gamma-secretase inhibitor decreases amyloidbeta production in the central nervous system. Ann Neurol 66:48-54.

Blennow K, de Leon MJ, Zetterberg H (2006) Alzheimer's disease. Lancet 368:387-403.

Burton CR, Meredith JE, Barten DM, Goldstein ME, Krause CM, Kieras CJ, Sisk L, Iben LG, Polson C, Thompson MW, Lin XA, Corsa J, Fiedler T, Pierdomenico M, Cao Y, Roach AH, Cantone JL, Ford MJ, Drexler DM, Olson RE, et al. (2008) The amyloid-beta rise and gamma-secretase inhibitor potency depend on the level of substrate expression. J Biol Chem 283:22992-23003.

Duff K, Suleman F (2004) Transgenic mouse models of Alzheimer's disease: how useful have they been for therapeutic development? Brief Funct Genomic Proteomic 3:47-59.

Gilberto DB, Zeoli AH, Szczerba PJ, Gehret JR, Holahan MA, Sitko GR, Johnson CA, Cook JJ, Motzel SL (2003) An alternative method of chronic cerebrospinal fluid collection via the cisterna magna in conscious rhesus monkeys. Contemp Top Lab Anim Sci 42:53-59.

Golde TE (2005) The Abeta hypothesis: leading us to rationally-designed therapeutic strategies for the treatment or prevention of Alzheimer disease. Brain Pathol 15:84-87.

Hardy J, Selkoe DJ (2002) The amyloid hypothesis of Alzheimer's disease: progress and problems on the road to therapeutics. Science 297:353-356.

Hock C, Konietzko U, Streffer JR, Tracy J, Signorell A, Müller-Tillmanns B, Lemke U, Henke K, Moritz E, Garcia E, Wollmer MA, Umbricht D, de Quervain DJ, Hofmann M, Maddalena A, Papassotiropoulos A, Nitsch RM (2003) Antibodies against beta-amyloid slow cognitive decline in Alzheimer's disease. Neuron 38:547-554.

Lanz TA, Hosley JD, Adams WJ, Merchant KM (2004) Studies of Abeta pharmacodynamics in the brain, cerebrospinal fluid, and plasma in young (plaque-free) $\operatorname{Tg} 2576$ mice using the gamma-secretase inhibitor N2[(2S)-2-(3,5-difluorophenyl)-2-hydroxyethanoyl]-N1-[(7S)-5-methyl6-oxo-6,7-dihydro-5H-dibenzo[b,d]azepin-7-yl]-L-alaninamide (LY-411575). J Pharmacol Exp Ther 309:49-55.

Lanz TA, Karmilowicz MJ, Wood KM, Pozdnyakov N, Du P, Piotrowski MA, Brown TM, Nolan CE, Richter KE, Finley JE, Fei Q, Ebbinghaus CF, Chen YL, Spracklin DK, Tate B, Geoghegan KF, Lau LF, Auperin DD, Schachter JB (2006) Concentration-dependent modulation of amyloid-beta in vivo and in vitro using the gamma-secretase inhibitor, LY-450139. J Pharmacol Exp Ther 319:924-933.

Lemere CA, Beierschmitt A, Iglesias M, Spooner ET, Bloom JK, Leverone JF, Zheng JB, Seabrook TJ, Louard D, Li D, Selkoe DJ, Palmour RM, Ervin FR (2004) Alzheimer's disease abeta vaccine reduces central nervous system abeta levels in a non-human primate, the Caribbean vervet. Am J Pathol 165:283-297.

Maillard I, Adler SH, Pear WS (2003) Notch and the immune system. Immunity 19:781-791.

Michener MS, Holahan MA, Gilberto DB, Sitko GR, Shearman MS, Harrison T, Lewis H, Sankaranarayanan S, Crouthamel M, Wu G, Pietrak BL, Simon AJ, Cook JJ (2006) P2-069: nonhuman primate model for prediction of human $\mathrm{A} \beta$ effects. Targeting $\gamma$-secretase: effects of enzyme inhibition vs modulation of cleavage specificity on CSF and plasma $A \beta$ in conscious rhesus monkeys. Alzheimers Dement [Suppl] 2:S252-S253.

Nantermet PG, Rajapakse HA, Stanton MG, Stauffer SR, Barrow JC, Gregro AR, Moore KP, Steinbeiser MA, Swestock J, Selnick HG, Graham SL, McGaughey GB, Colussi D, Lai MT, Sankaranarayanan S, Simon AJ, Munshi S, Cook JJ, Holahan MA, Michener MS, et al. (2009) Evolution of tertiary carbinamine BACE-1 inhibitors: Abeta reduction in rhesus CSF upon oral dosing. ChemMedChem 4:37-40.

Portelius E, Price E, Brinkmalm G, Stiteler M, Olsson M, Persson R, Westman-Brinkmalm A, Zetterberg H, Simon AJ, Blennow K (2009) A novel pathway for amyloid precursor protein processing. Neurobiol Aging. Advance online publication. Retrieved July 14, 2009. doi:10.1016/j.neurobiolaging.2009.06.002.

Rosen LB, Stone JA, Plump A, Yuan J, Harrison T, Flynn M, Dallob A, Matthews C, Stevenson D, Schmidt D, Palmieri T, Leibowitz M, Jhee S, Ereshefsky L, Salomon R, Winchell G, Shearman MS, Murphy MG, Gottesdiener KM (2006) O4-03-02: the gamma secretase inhibitor MK0752 acutely and significantly reduces CSF A 340 concentrations in humans. Alzheimers Dement [Suppl] 2:S79-S79.

Sankaranarayanan S, Holahan MA, Colussi D, Crouthamel MC, Devanarayan V, 
Ellis J, Espeseth A, Gates AT, Graham SL, Gregro AR, Hazuda D, Hochman JH, Holloway K, Jin L, Kahana J, Lai MT, Lineberger J, McGaughey G, Moore KP, Nantermet P, et al. (2009) First demonstration of cerebrospinal fluid and plasma $\mathrm{A}$ beta lowering with oral administration of a beta-site amyloid precursor protein-cleaving enzyme 1 inhibitor in nonhuman primates. J Pharmacol Exp Ther 328:131-140.

Searfoss GH, Jordan WH, Calligaro DO, Galbreath EJ, Schirtzinger LM, Berridge BR, Gao H, Higgins MA, May PC, Ryan TP (2003) Adipsin, a biomarker of gastrointestinal toxicity mediated by a functional gammasecretase inhibitor. J Biol Chem 278:46107-46116.

Siemers E, Skinner M, Dean RA, Gonzales C, Satterwhite J, Farlow M, Ness D, May PC (2005) Safety, tolerability, and changes in amyloid beta concentrations after administration of a gamma-secretase inhibitor in volunteers. Clin Neuropharmacol 28:126-132.

Siemers ER, Quinn JF, Kaye J, Farlow MR, Porsteinsson A, Tariot P, Zoulnouni P, Galvin JE, Holtzman DM, Knopman DS, Satterwhite J, Gonzales C, Dean RA, May PC (2006) Effects of a gamma-secretase inhibitor in a randomized study of patients with Alzheimer disease. Neurology 66:602-604.

Stanger BZ, Datar R, Murtaugh LC, Melton DA (2005) Direct regulation of intestinal fate by Notch. Proc Natl Acad Sci U S A 102:12443-12448.

Steiner H, Fluhrer R, Haass C (2008) Intramembrane proteolysis by gamma-secretase. J Biol Chem 283:29627-29631.

Struble RG, Price DL Jr, Cork LC, Price DL (1985) Senile plaques in cortex of aged normal monkeys. Brain Res 361:267-275.
Tomita T (2009) Secretase inhibitors and modulators for Alzheimer's disease treatment. Expert Rev Neurother 9:661-679.

Vassar R (2004) BACE1: the beta-secretase enzyme in Alzheimer's disease. J Mol Neurosci 23:105-114.

Wolfe MS (2008a) Selective amyloid-beta lowering agents. BMC Neurosci 9 Suppl 2:S4.

Wolfe MS (2008b) Inhibition and modulation of gamma-secretase for Alzheimer's disease. Neurotherapeutics 5:391-398.

Wolfe RR, Chinkes DL, Wolfe RR (2005) Isotope tracers in metabolic research: principles and practice of kinetic analysis, Ed 2. Hoboken, NJ: Wiley.

Wong GT, Manfra D, Poulet FM, Zhang Q, Josien H, Bara T, Engstrom L, Pinzon-Ortiz M, Fine JS, Lee HJ, Zhang L, Higgins GA, Parker EM (2004) Chronic treatment with the gamma-secretase inhibitor LY411,575 inhibits beta-amyloid peptide production and alters lymphopoiesis and intestinal cell differentiation. J Biol Chem 279:12876-12882.

Yan P, Hu X, Song H, Yin K, Bateman RJ, Cirrito JR, Xiao Q, Hsu FF, Turk JW, Xu J, Hsu CY, Holtzman DM, Lee JM (2006) Matrix metalloproteinase-9 degrades amyloid-beta fibrils in vitro and compact plaques in situ. J Biol Chem 281:24566-24574.

Yarasheski KE, Smith K, Rennie MJ, Bier DM (1992) Measurement of muscle protein fractional synthetic rate by capillary gas chromatography/ combustion isotope ratio mass spectrometry. Biol Mass Spectrom 21: $486-490$. 